\title{
VISITAS RESTRITAS A CRIANÇAS HOSPITALIZADAS: UMA BARREIRA PARA A INTERAÇÃO MÃE-FILHO
}

\author{
Margareth Angelo*
}

ANGELO, M. Visitas restritas a crianças hospitalizadas: uma barreira para a interação mãe-filho. Rev. Esc. Enf. USP, São Paulo, 17(3):229-234, 1983.

A autora apresenta resultados de obscrvasoôes realizadas em três hospitais pediátricos, quanto à promofão do relacionamento mãe-filho hospitalizado. Constatando ser a visita a única oportunidade para não ser interrompido o contato da mãe com a criança, discute alguns efeitos da visita restrita sobre o relacionamento mãe-filho. Além disso, aponta a necessidade de incluir a mãe na assistência a essa crianşa, para o bem- estar de ambos.

Muitos autores têm apontado que a criança necessita de um relacionamento carinhoso, próximo e contínuo com a mãe e que, se separadas por um período prolongado de tempo, a saúde e bem-estar da criança podem ser prejudicados.

BOWLBY ${ }^{3}$, em seus trabalhos sobre privação materna, e ROBERTSON ${ }^{17}$, em seus estudos sobre a criança pequena no hospital, enfatizam a necessidade que a criança tem da presença da mãe, sugerindo a não interrupção do relacionamento mãe-filho, para o bom desenvolvimento da criança.

A aceitação e compreensão do fenômeno "relacionamento criança-mãe" é necessária para a formação do enfermeiro, devendo ser encarado como algo sujeito à sua intervenção, tendo em vista que este profissional é o responsável pela manutenção e promoção do ambiente emocional adequado à criança hospitalizada. Sendo assim, é sua a responsabilidade de atuar junto aos pais, porque eles fazem parte do ambiente emocional da criança, protegendo e fortalecendo o relacionamento deles com o filho, durante a hospitalização.

Verifica-se que a presença da mãe junto ao filho hospitalizado tem sido vista por vários autores como benéfica, tanto para a criança como para a própria mãe, sendo propostas, por este motivo, várias medidas para a não interrupção do relacionamento durante a internação da criança.

\footnotetext{
* Enfermeira. Mestre em Enfermagem. Professor Assistente do Departamento de Enfermagem Materno-Infantil e Psiquiátrica da Escola de Enfermagem da USP - disciplína Enfermagem Pediátrica.
} 
PRUGH et alii ${ }^{15}$ são de opinião que a presença e a participação dos pais no hospital, durante a internação, constituem a chave para o apoio emocional à criança.

AUFHAUSER ', BURROWS ${ }^{\text {' }}$ e HARDGROVE \& RUTLEDGE ' apresentam maneiras para estimular a participação da mãe no cuidado do filho no hospital, indicando que o envolvimento em atividades de cuidado à criança fortalece o relacionamento dos dois.

Alguns autores, como GARTON ", HOLMAN ", JEFFERIES ${ }^{11}$, MORGAN ${ }^{1: 3}$, O'CONNEL \& BRANDT ${ }^{14}$ e STEVENS ${ }^{19}$, defendem a idéia de visitas irrestritas para o paciente, principalmente para a criança, uma vez que ela precisa da mãe e essa necessidade aumenta quando está doente. Os autores também chamam a visita irrestrita de liberal, aberta ou livre, significando, este tipo de visita, que os pais podem visitar o filho hospitalizado 24 horas por dia, nos 7 dias da semana, ou seja, os pais têm livre acesso ao hospital.

Estas informaçōes determinaram o interesse em verificar quais as normas de três hospitais pediátricos da cidade de São Paulo, referentes à promoção relacionamento mãe-criança internada.

Após observações, constatou-se a seguinte situação:

- Hospital 1: restringia o número de horas diárias de visita a $2 \mathrm{~h} 30 \mathrm{~m}$, permitindo o contato físico entre mãe e filho, ou seja, a mãe poderia carregar a criança no colo, dar-lhe mamadeira, trocar sua fralda, e dar-lhe outros cuidados simples.

- Hospital 2: restringia o número de visitas a 4 dias da semana, com uma hora de duração. Além disso, somente as crianças possibilitadas de saírem do leito (as que não estivessem em repouso ou recebendo terapia endovenosa, por exemplo) poderiam entrar em contato com a mãe, porém, fora das enfermarias, no corredor. As que não pudessem sair do leito eram vistas pelas mães através de visores existentes nas portas das enfermarias.

- Hospital 3: restringia o número de visitas a 4 dias da semana, e a duração da mesma a 30 minutos. Nesse período, as mães limitavam-se a olhar os filhos através de um visor localizado entre o corredor de circulação da unidade e as enfermarias, não sendo possivel, portanto, qualquer interação, que não a visual, com a criança.

Percebe-se, por estas informações, que os 3 hospitais determinam restriçōes ao relacionamento mãe-filho, e que a principal diferença entre as visitas, nesses hospitais, reside na natureza da interação permitida entre mãe e filho, ocorrendo apenas como contato visual no hospital 3, proximidade pouco maior no segundo e oportunidade para envolvimento da mãe na assistência ao filho no hospital 1.

As observações feitas permitem, ainda, concluir que a visita, nesses hospitais, é a única oportunidade para não ser interrompida totalmente a relação mãe-criança hospitalizada. 
Apesar da possibilidade de contato da família com o doente ser representada pela visita, esta pode ser qualificada como restrita, tanto nos aspectos de freqüência e duração dos contatos, como também no que diz respeito à interação da mãe com a criança.

Para GODFREY ", a visita restrita é uma panacéia, porque a ansiedade da separação continua.

BEARDEN ${ }^{2}$ considera que a visita é uma ocasião para interação, significando que existe na relação do paciente com o visitante, as necessidades de cada um opondo-se ao outro em um equilíbrio rítmico, e que cada pessoa individualmente, deve ser vista com suas próprias necessidades e a pessoa oposta como o ambiente onde suas necessidades podem ser satisfeitas.

Pensando na interação da criança com a mãe, durante a situação de visita restrita nos hospitais observados, nota-se que a restrição é inadequada, por não estarem sendo oferecidas condições para que o relacionamento aconteça de fato,

No que diz respeito à interação da mãe com algum profissional de saúde durante a visita, a situação parece ser mais crítica ainda, pois verificou-se que as mães geralmente entravam e saíam das unidades, nos períodos de visita, sem trocar palavra com pessoa alguma, dando a impressão de a visita ser algo apenas entre o paciente e o visitante.

Diante desses fatos, pode-se pensar que a visita parece ser apenas um procedimento regido por normas, regulamentos e até preferências dos hospitais, e que às pessoas da equipe hospitalar só resta a responsabilidale de transmitir as regras de visitas aos familiares e verificar se estão sendo seguidas corretamente, sem a preocupação de analisar os efeitos que tais determinações possam estar causando ao paciente e aos visitantes.

ROSKIES et alii ${ }^{18}$ referem que, muitas vezes, as mães são incapazes de dar apoio psicológico ao seu filho durante a hospitalização, devido às suas próprias incertezas sobre seu papel na estrutura hospitalar, e que esse desconforto é muitas vezes reforçado pela equipe hospitalar que, incomodados pela invasão de seu território por estranhos, tende a comunicar à mãe ser ela uma intrusa, uma transmissora de infecções e provocadora de distúrbios emocionais na criança.

RAMOS \& MORAES ${ }^{14}$ indicam que uma parte importante do tratamento da criança é reduzir a ansiedade dos pais, oferecendo-lhes apoio para expressarem seus sentimentos, e que a mãe experimenta a ajuda, durante um relacionamento positivo com um profissional da equipe de saúde.

Estes trabalhos sugerem que cabe ao pessoal do hospital, especialmente ao enfermeiro, a responsabilidade de atuar junto à mãe, sobretudo enquanto visitante.

Os fatos expostos, parecem indicar serem inadequados tanto o relacionamento entre mãe e filho, como entre mãe e equipe hospitalar. 
Note-se que os impedimentos para estas interações, podem ser percebidos através de situações concretas, como um visor na parede e o desaparecimento da equipe hospitalar durante a visita, mas também por formas menos evidentes, porém muito freqüentes, que dificultam e mesmo impedem o relacionamento no momento da visita, caracterizadas por demonstração de desaprovação, por parte da equipe, das ações das mães junto ao filho ou comunicações bruscas com o visitante, quando este tenta abordar algum elemento da equipe.

A inadequação ao relacionar-se com o outro, segundo BEARDEN ${ }^{2}$, origina-se de percepções erradas ou da incapacidade para atuar sobre as percepções do outro, estando estes aspectos intimamente relacionados.

Supõe-se não ser intenção dos administradores hospitalares, ao determinarem normas restritivas para as visitas, causar transtornos no relacionamento mãe-filho; não se sabe o que consideram para propor tal situação limitante de relacionamento; pode-se até supor que desconheçam os efeitos negativos que essas regras podem ter sobre as mães e as crianças.

Esta é uma situação preocupante, pois fica evidente a ruptura do relacionamento familiar, ainda mais ao se imaginar que nada parece estar sendo feito nos hospitais observados para melhorar a situação da visita, porque ela pode estar sendo considerada como uma norma que não podo ser modificada, porque afetaria o bom andamento do hospital.

Não se sabe se esse fato é decorrente da falta de conhecimento dos profissionais e conseqüente dificuldade em visualizar meios para mudança, ou se o problema não é percebido, ou até mesmo se não há interesse em mudar, uma vez que a mudança implicaria em reformulação de normas, e até de papéis, sendo portanto trabalhosa e inoportuna.

Lembrando a afirmação de que "a filosofia básica do hospital para com seus pacientes e familiares está refletida em seus procedimentos de rotina" ${ }^{12}$, conclui-se que as visitas nos referidos hospitais não podem continuar como são, porque a mensagem que estão transmitindo é a de que a presença dos pais em suas dependências não é desejada.

HARDGROVE $^{8}$ apresenta 2 motivos principais que justificam a presença dos pais no hospital:

- normalizar o ambiente, reduzindo a ansiedade da criança, pois para ela a presença dos pais significa segurança.

- dar continuidade ao desenvolvimento da criança e da família.

O modo como os hospitais estão organizados, parece indicar a intenção de monopolizar a assistência à criança, contrariando a tendência atual para a assistência à saúde, que é a capacitação do individuo para o auto-cuidado e que, no caso da criança, deve ser desenvolvido pelos pais. Além disso, é preciso ter-se em mente que a criança e seus problemas de saúde pertencem aos pais; e que cabe aos profissionais de saúde a função de apoiá-los e de apresentar recursos para a resolução 
dos problemas, e não de resolvê-los por eles, privando-os dessa importante situação de aprendizagem. Por isso, compete ao enfermeiro capacitar a mãe a observar e ajudar o filho, sobretudo durante a doença. Esse cuidado não pode deixar para ser aprendido no momento da alta, porque fatalmente seria interrompido com a saida da criança do hospital. Essa interrupção implicaria, entre outras coisas, em possível reinternação da criança, uma vez que a mãe poderia não ter tido oportunidade e tempo suficiente para desenvolver sua capacidade para perceber e atender a todas as necessidades do filho no domicílio.

As visitas devem tornar-se menos restritas, principalmente no que diz respeito às interações, tanto com o paciente, como com os membros da equipe. $\mathrm{E}$ preciso que sejam desenvolvidas normas que garantam a presença dos pais no hospital, e que essa presença seja aproveitada para benefício de todos os envolvidos.

Não se pretende dizer com isso que os hospitais devam passivamente abrir suas portas para que todas as mães entrem, pois isso apenas serviria para causar mais transtornos além dos que provavelmente acontecem. Antes, é preciso que o pessoal hospitalar, especialmente o de enfermagem, modifique sua atitude para com os pais, e passe a encará-los como um auxílio necessário e não como um impecilho para a assistência à criança. Acreditamos que a atitude do pessoal de enfermagem muda à medida em que convivem com os pais, querendo aprender a ajudá-los.

A transformação da visita implicaria, certamente, na reformulação de papéis, especialmente o do enfermeiro. Como diz ISSNER ${ }^{10}$, o papel da enfermeira não é o de suplantar a familia, mas o de suplementá-la, no objetivo comum do bem-estar da criança.

Assim considerando, a presença da mãe não determinaria uma restrição nos domínios de ação do enfermeiro, mas uma ampliação, pois ela estenderia sua responsabilidade a mais um membro da família: a mãe.

Além dessa modificação facilitar os contatos da mãe com o enfermeiro, possibilitando melhor compreensão da criança e permitindo a adequação da assistência de enfermagem, resultando num cuidado realmente efetivo, não ocorreria a exclusão da mãe, no momento em que a criança mais precisa dela.

Finalizando, cabe assinalar que somente quando a visita deixar de ser restrita, em todos os aspectos, tornar-se-á uma situação de crescimento para todos os envolvidos.

ANGELO, M. Restricted visiting for hospitalized children: a barrier to mother-child interaction. Rev. Esc. Enf. USP, São Paulo, 17(3):229-234, 1983.

The author presents data concerning mother-child relationship promotion, results of her observations in three pediatric hospitals. Verificating that the visit represents the sole opportunity for not breaking mother-child contact, the author discusses some effects of the restricted visit upon mother-child relationship, pointing out the need of including the mother in the child's care. 


\section{REFERENCIAS BIBLIOGRAFICAS}

1. AUfHAUSER, T. R. Parent participation in hospital care of children. Nurs. Outlook, New York, 15(1):40-2, 1967.

2. BEARDEN, F. C. An interactional approach to hospital visiting. J. Psychiatr. Nurs., Thorofare, 10(4):16-7, 1972.

3. BOWLBY, J. Maternal care and mental health. New York, Schocken, 1966.194 p.

4. BURRows, J. M. The child and his family. Nurs. Times, London, 69(39):1266-7, 1973.

5. GartoN, E. J. In praise of open visiting. Nurs. Times, London, 75(41):1747, 1979.

6. GODFREY, A. E. A study of nursing care designed to assist hospitalized children and their parents in their separation. Nurs. Res., New York, 4(2):52-69, 1955.

7. HARDGRove, C. \& RUTLEDGE, A. Parenting during hospitalization. Amer. J. Nurw., New York, 75(5):836-8, 1975 .

8. HARGROVE, C. Helping parents on the pediatric ward: a report on a survey of hospitals with living-in programs. Pediatrician, Basel, 9(4):220-3, 1980.

9. HOLMAN, D. The heartbreak continues. Nurs. Mirror, Sussex, 132(22):12, 1971.

10. ISSNER, N. The family of the hospitalized child. Nurs. Clin. North Amer., Philadelphia, $7(1): 5-12,1972$

11. JEFFERIES, P. M. Free visiting for children. Nurs. Times, London, 69(49):1664-5, 1973.

12. LIBERAL visiting policies for children in hospitals: a report by the citizens comittee on children of New York City. J. Pediatr., Saint Louis, 46(1):710-6, 1955.

13. MORGAN, B. O. Visiting in children's units: a changing pattern. Nurs. Times, London, 63(51):1711-4, 1967 .

14. O'CONNELL, E. A. \& BRANDT, P. Liberal visiting hours for parents. Amer. J. Nurs., New York, 60(6):812-5, 1960 .

15. PRUGH, D. G. et alii. A study of the emotional reactions of children and families to hospitalization and illness. Amer. J. Orthopsychiatry, New York, 23(1):70-106, 1953.

16. RAmOS, T. A. G. \& MORAES, E. Papel da enfermeira junto a mães de crianças hospitalizadas. Rev. Bras. Ent., Brasllia, 29(2):45-55, 1976.

17. ROBERTSON, J. Hospitals and children. New York, International Universitles Press, 1962. p. 13-9.

18. ROSKIES, E. et alil. Increasing maternal participation in the hospitalization of young children. Med. Care, Philadelphia, 16(9):765-77, 1978.

19. STEVENS, M. Vigitors are welcome on the pediatric ward. Amer. J. Nurs., New York, $49(4): 233-5,1949$. 